DOI: 10.15587/2519-4852.2021.249634

\title{
IDENTIFICATION OF BENZYDAMINE AND ITS METABOLIT IN THE PRESENCE OF CERTAIN ANTI-INFLAMMATORY NON-STEROIDAL DRUGS
}

\author{
Olga Chorna, Vasyl Chornyi, Alexander Chubenko, Ihor Hrubnyk, Volodymyr Mishchenko, \\ Mykola Golik
}

The aim of the work. Currently, a large number of cases of non-medical use of benzydamine hydrochloride have been described. The identification of benzydamine and its metabolite, benzydamine N-oxide, in the presence of some non-steroidal anti-inflammatory drugs, has been insufficiently studied. Therefore, the development of a method for its identification in biological material is an urgent task.

Materials and methods. The subjects of the study were benzydamine hydrochloride and its metabolite, as well as some non-steroidal anti-inflammatory drugs, which are its analogues in terms of pharmacological action. The studies were carried out by methods of thin layer chromatography and high-performance liquid chromatography. Results. At the first stage a screening method for benzydamine identification was studied using the extraction in acidic and basic conditions. It was shown that benzydamine can be isolated in both medias with subsequent development with a solution of iodoplatinate and Dragendorff's reagent according to Munier or with Mandelin reagent respectively. The mobile phase was selected and respective hRffor the target molecule were defined.

After a preliminary identification of benzydamine a reference method for the final confirmation of the drug that had led to poisoning was proposed. A robust, specific and accurate reversed phase HPLC method was chosen. It was shown that benzydamine exists in biological material mainly in a form of metabolite - benzydamine $N$-oxide. The selected method was able to separate and determine key analytes in biological samples after a preparative isolation by TLC method. The comparison with UV spectra of the reference standard of benzydamine hydrochloride was proposed to avoid false positive conclusion of drug identification.

Conclusions. Proposed methodology can be applied for routine identification of benzydamine poisoning in toxicological laboratories

Keywords: benzydamine hydrochloride, screening, benzydamine N-oxide, thin layer chromatography, high-performance liquid chromatography

\author{
How to cite: \\ 4852.2021.249634 \\ (C) The Author(s) 2021 \\ This is an open access article under the Creative Commons CC BY license hydrate
}

Chorna, O., Chornyi V., Chubenko, A., Hrubnyk, I., Mishchenko, V., Golik M. (2021). Identification of benzydamine and its metabolit in the presence of certain anti-inflammatory non-steroidal drugs. ScienceRise: Pharmaceutical Science, 6 (34), 43-50. doi: http://doi.org/10.15587/2519-

\section{Introduction}

Non-steroidal anti-inflammatory drugs (NSAIDs) are currently one of the most widely used drugs in the world. It is estimated that 30 million people take NSAIDs a day [1]. This is due to the fact that they are prescribed for pain of various etiologies and used during drug withdrawal. The release of most of these substances is over the counter. One of such drugs are drugs based on benzydamine hydrochloride, which has analgesic, antipyretic and anti-inflammatory effects. It is prescribed to reduce postoperative and post-traumatic complications. Also, this drug is used externally in the treatment of rheumatic diseases and inflammation of the mouth and throat [2]. In case of overdose, a psychostimulant effect on the CNS due to activation of anticholinergic receptors was noted [3]. Cases of non-medical use of benzydamine hydrochloride an among adolescents have been reported in a number of countries, in particular in Romania, Poland [3], United Kingdom [4], Brazil [5, 6], Turkey [7-10], Italy [11], British [12].

The appearance on the pharmaceutical market of new drugs - potential objects of non-medical use, one of which is benzydamine hydrochloride [13], actualizes the problem of its reliable detection and identification by analytical toxicology methods, in particular, by thin layer chromatography and high-performance liquid chromatography. This method allows both "screening" for groups of drugs united by structural or pharmacological commonality, and identification. When conducting toxicological studies of a particular drug, its properties are compared either with analogues in structure or pharmacological action, so in our case we chose to study the following widely used nonsteroidal anti-inflammatory drugs: diclofenac, nimesulide, mefenamic acid, propiphenazone, indomethacin, piroxycam and meloxicam, which have a similar pharmacological action.

The widespread use of this group of drugs in medical practice, along with benzydamine, set the task of studying the possible obtaining of cross-false positive results when using thin layer chromatography. First of all, this refers to the results obtained when using reagents-visualizers in "TLC-screening", as well as when determining the chromatographic mobility of the studied drug in comparison with the anti-inflammatory drugs given. 
Benzydamine hydrochloride is N, N-Dimethyl-3 [[1- (phenylmethyl) -1H-indazol-3-yl] oxy] -1-propanamine (in the form of hydrochloride) (Fig. 1) [14].

This is a white powder with a melting point of $160{ }^{\circ} \mathrm{C}$, boiling point 474.4 . It is soluble in water and alcohols, chloroform, DMSO. Its molecular weight is 345.87 , the molecular formula is $\mathrm{C} 19 \mathrm{H} 24 \mathrm{~N} 3 \mathrm{OCl}$.

Benzidamine base has $\mathrm{pKa}=9.26$ and is a crystalline substance with a boiling point of $160{ }^{\circ} \mathrm{C}$.

The aim of the work. Development of methodology of determination of benzydamine hydrochloride and its main metabolite in biological material in order to diagnose poisoning and provide timely medical care.<smiles></smiles>

Fig. 1. Structural formula of benzydamine hydrochloride

\section{Planning (methodology) of research}

It was necessary to reliably determine the place of benzydamine when performing "TLC-screening" and to propose a method for its identification. To solve the problem, the following steps should be taken. Most of NSAIDs that were studied (except for propifenazone) have weakly acidic properties or have two stages of dissociation, therefore, when isolated from biological material, they are in an acidic extract. The $\mathrm{pKa}$ value of benzydamine determines its place in the alkaline extract (Fig. 2).

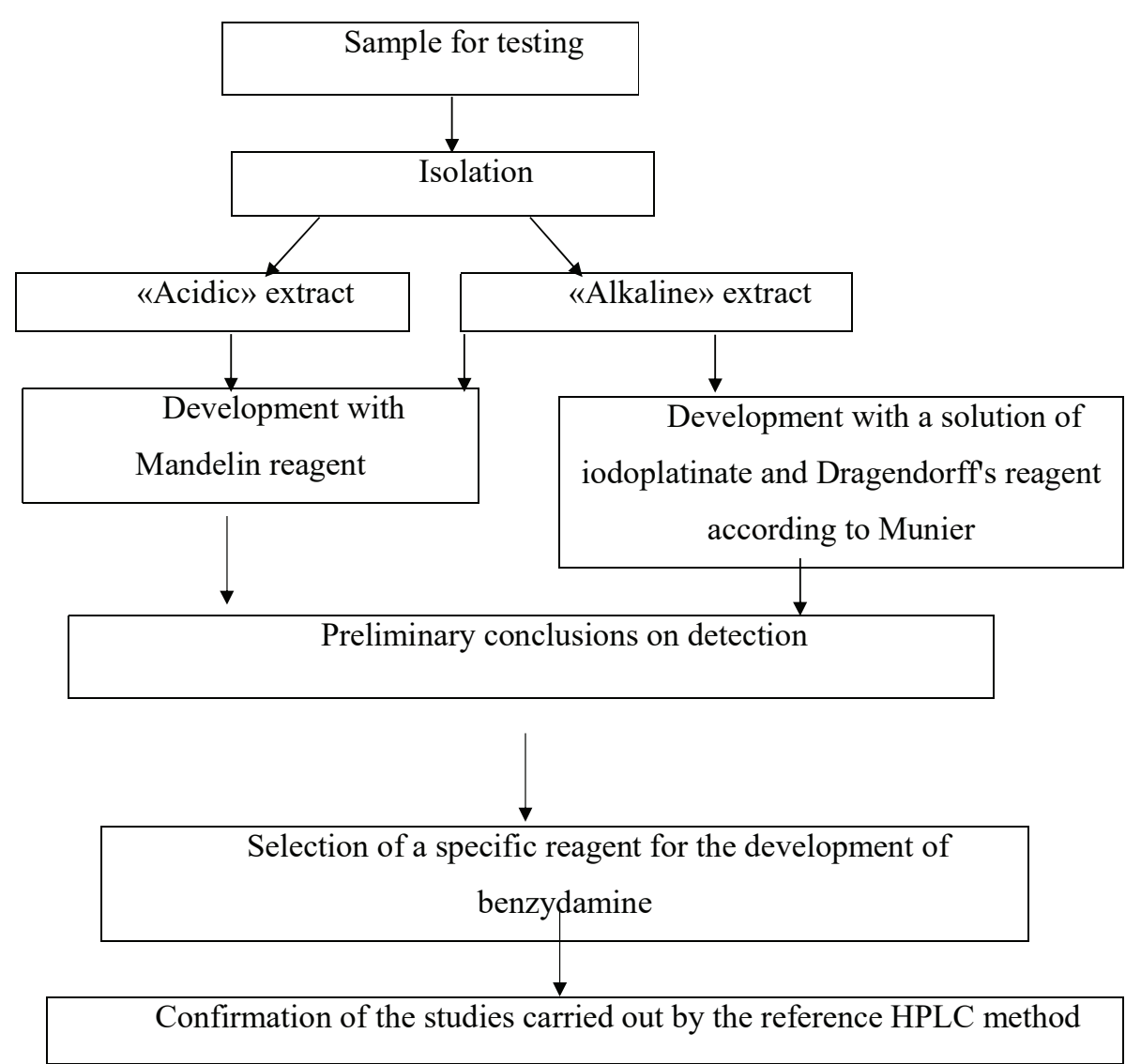

Fig. 2. Decision tree

\section{Materials and methods}

To obtain acidic NSAID extracts, a sample of the drug ( 2 tablets of each drug) was ground in a mortar, and the resulting powder was shaken for 10 minutes with twice the amount of water. Then hydrochloric acid was added to $\mathrm{pH}=1-2$ and extracted with equal volumes of chloroform. Chloroform extracts were combined and filtered through a paper filter with anhydrous sodium sulfate. The combined extracts were slowly evaporated to give acidic drug extracts in chloroform.

To obtain alkaline extracts of NSAIDs, samples of drugs were taken again, ground in a mortar, and the resulting powder was shaken for 10 minutes with twice the amount of water. Then a $25 \%$ ammonia solution was added to $\mathrm{pH}=9-10$ and extraction was performed twice with equal volumes of chloroform. Chloroform extracts were combined and filtered through a paper filter with anhydrous sodium sulfate. The combined extracts were slowly evaporated to give alkaline extracts in chloroform.

Diclofenac, mefenamic acid, propifenazone, and indomethacin were found to be removed at $\mathrm{pH} 2$, and only nimesulide and benzydamine were removed at $\mathrm{pH} 2$ and $\mathrm{pH} 9-10$.

The pharmacopoeial standard of the British Pharmacopoeia was purchased as a reference sample of benzydamine hydrochloride. Standard solutions of other NSAIDs were prepared from dosage forms to obtain acidic and alkaline extracts.

Sample preparation and TLC analysis were carried out under following conditions: benzydamine hydrochloride was ground in a mortar, and the obtained powder was shaken for 10 minutes with twice the amount of water. Then a $25 \%$ ammonia solution was added to $\mathrm{pH}=9-10$ and the benzydamine base was extracted twice with equal volumes of chloroform. Chloroform extracts were combined and filtered through a paper filter with anhydrous sodium sulfate. The combined extracts were slowly evaporated to give a $0.1 \%$ solution of benzydamine base in chloroform.

For the study of the possibility of detection of benzydamine and its metabolite in real urine samples of patients who took it, the following procedure was proposed.

Sampling and research were conducted in the toxicology laboratory of the Kharkiv Regional Narcological Dispensary.

$50 \mathrm{ml}$ of the studied urine was acidified with $10 \%$ hydrochloric acid to $\mathrm{pH}=2-3$ and a single extraction of $50 \mathrm{ml}$ of chloroform was performed. The resulting acid chloroform ex- 
tract was separated, and the aqueous phase was basified with $25 \%$ ammonia solution to $\mathrm{pH}=9$ and extracted twice with $25 \mathrm{ml}$ of chloroform. The combined alkaline extracts and the previously obtained acidic extract were filtered separately through filters with anhydrous sodium sulfate, evaporated in a stream of cold air to volumes of $1 \mathrm{ml}$ and used for further studies.

The studies were performed by normal-phase chromatography on Sorbfil plates (PTSH - P - A - UV silica gel; $10 \times 10 \mathrm{~cm}) .20 \mu \mathrm{l}$ of $0.1 \%$ solutions of test substances were applied to the starting line at a distance of $1.5 \mathrm{~cm}$ from the lower edge of the plate and, after drying in air, was placed in a chamber.

Chromatography was performed three times in unsaturated glass chambers with a volume of $500 \mathrm{ml}$ containing $10 \mathrm{ml}$ of mobile phase, which was used once.

After lifting the mobile phase to a distance of $8 \mathrm{~cm}$, the plate was removed, dried in the air to remove the odor of solvents and treated with a suitable developer.

HPLC determination was carried out under following conditions:

Chromatographic study was performed using a Shimadzu LC-20 liquid chromatograph with a diode-array detector, autosampler, degasser and quaternary pump. LC Solution software was used to collect the data.

- Grace Alltima C18 column with a size of $250 * 4.6 \mathrm{~mm}$, with a particle size of $5 \mu \mathrm{m}$;

- mobile phase: $3.0 \mathrm{~g}$ of sodium perchlorate $\mathrm{P}$ was dissolved in $500 \mathrm{ml}$ of water $\mathrm{P}$, added $1.0 \mathrm{ml}$ of triethylamine $\mathrm{P}$, adjusted the $\mathrm{pH}$ with perchloric acid $\mathrm{P}$ to 3.0 , added $500 \mathrm{ml}$ of acetonitrile $\mathrm{R}$;

- flow rate $-1 \mathrm{ml} / \mathrm{min}$;

- detection at a wavelength of $320 \mathrm{~nm}$ for benzydamine;

- column thermostat temperature $25^{\circ} \mathrm{C}$;

- as a solvent used a mixture of water $\mathrm{P}$ : acetonitrile $P$ in a ratio of $1: 1$.

Chromatography was carried out using 20 $\mu \mathrm{l}$ of both reference and test solutions.

\section{The results of the study}

A sample of benzydamine hydrochloride was converted to the base, which was used in further studies.

The results of chromatographic separation are presented in Table 1.

As the systems 1-3 do not give sufficient separation of the tested substances, we proposed the use of a known method for detection of the nonsteroidal anti-inflammatory substances and some other substances and acids by TLC $[15,16]$, which increases the likelihood of identification of these substances in human urine after extraction from acidic and alkaline environment due to the use of reagents developers. Secondly, an attempt was made to study two extracts of benzydamine hydrochloride - acidic and alkaline and the development of the latter with bromocresol green in acetic acid.

According to the literature [17], benzydamine is found in blood plasma in an amount insufficient to obtain systemic effects and is excreted mainly by the kidneys in the form of inactive metabolites or conjugation products. The main metabolite and degradation product of benzydamine hydrochloride is benzydamine N-oxide $[18,19]$. The metabolism scheme is shown in the Fig. 3.

The results obtained are presented in Table 2.

In practice, the preliminary identification of substances is based on literature data: in the case of using of the TLC method - the coincidence of the value of hRf substances and specific color [20]. Based on the above data - when the value of the hRf of the substances under study, with tabular, as well as when observing the occurrence of the corresponding color, after treatment of the plates with appropriate reagents, it is possible to make a preliminary conclusion about the presence of test substances.

As follows from the obtained data, the hRf of benzydamine coincides with the literature data, which allows us to conclude about the preliminary identification of benzydamine.

To confirm the established structure, it is advisable to use an alternative technique that allows efficient separation and determination of substances analyzed in complex mixtures. The most common method for solving this problem is high-performance liquid chromatography.

Table 1

The results of the chromatographic distribution of nonsteroidal anti-inflammatory drugs

\begin{tabular}{|c|c|c|c|c|c|c|}
\hline \multirow{2}{*}{ Substance } & \multicolumn{3}{|c|}{ Staining with reagents } & \multicolumn{3}{c|}{$\begin{array}{c}\text { hRf in systems* } \\
(n=5, P=95)\end{array}$} \\
\cline { 2 - 7 } & I. & II. & III. & 1 & 2 & 3 \\
\hline Benzydamine & brown & oranges & $\begin{array}{c}\text { brown- } \\
\text { green }\end{array}$ & $41 \pm 3$ & $57 \pm 2$ & $45 \pm 3$ \\
\hline Diclofenac & $\begin{array}{c}\text { grey- } \\
\text { brown }\end{array}$ & brown & $\begin{array}{c}\text { brown- } \\
\text { black }\end{array}$ & $10 \pm 4$ & $12 \pm 3$ & $81 \pm 3$ \\
\hline $\begin{array}{c}\text { Indomethacin } \\
\text { light } \\
\text { brown }\end{array}$ & yellow & brown & $43 \pm 2$ & $8 \pm 3$ & $71 \pm 3$ \\
\hline Meloxicam & yellow & - & yellow & $16 \pm 3$ & $11 \pm 3$ & $45 \pm 2$ \\
\hline $\begin{array}{c}\text { Mefenamic } \\
\text { acid }\end{array}$ & grey & - & blue-blue & $78 \pm 2$ & $20 \pm 5$ & $77 \pm 3$ \\
\hline Nimesulide & yellow & oranges & oranges & $77 \pm 3$ & $33 \pm 2$ & $82 \pm 3$ \\
\hline Piroxicam & - & oranges & - & $71 \pm 3$ & $10 \pm 4$ & $83 \pm 3$ \\
\hline $\begin{array}{c}\text { Propifena- } \\
\text { zone }\end{array}$ & yellow & yellow & light grey & $73 \pm 3$ & $80 \pm 2$ & $78 \pm 5$ \\
\hline
\end{tabular}

Note: *-Solvent systems: chloroform-acetone (9:1); toluene-acetone ethanol ammonia (4.5:4.5:0.75:0.25); methanol - $25 \%$ ammonia (100:1.5). Reagents - developers: I. Iodplatinate reagent; II. Dragendorf reagent by Mounier; III. Mandelin reagent

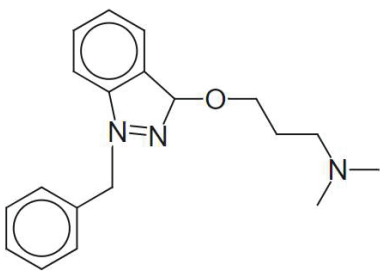

Benzydamine

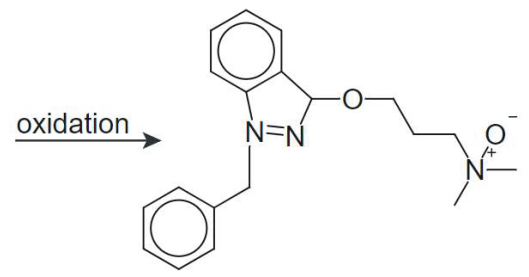

Benzydamine N-oxide
Fig. 3. Scheme of benzydamine metabolism/degradation 
The determination of benzydamine and its metabolite was carried out according to the previously developed method for the identification of benzydamine hydrochloride [20], the spectrum of which is shown in the Fig. 4.

For additional identification of benzydamine, the UV spectrum of benzydamine from the reference solution (Fig. 5) was taken for the further comparison with the spectrum in the test solution.

Chromatogram (Fig. 6) and UV spectrum of benzydamine N-oxide (Fig. 7) were recorded for additional identification of peaks.
It was shown that UV spectrums of benzydamine and benzydamine $\mathrm{N}$-oxide have a very similar profile, with a specific maximum at $307 \mathrm{~nm}$.

TLC chromatography was performed under the conditions described above.

For the final identification and confirmation of the substances under study, the HPLC method was used after preparative purification of the biomaterial sample.

To address this issue, the respective areas on the plate were subjected to chromatographic purification by

The results of visualization of the chromatographic distribution

\begin{tabular}{|c|c|c|c|c|c|}
\hline Substance & IV* & $\mathrm{V}^{*}$ & VI* & VII* & VIII* \\
\hline Diclofenac & - & brown & purple & yellow & - \\
\hline Nimesulide & yellow & yellow & yellow & green & - \\
\hline Mefenamic acid & - & brown & purple & yellow & - \\
\hline Propifenazone & - & blue & red & - & - \\
\hline Benzydamine hydrochloride standard & - & white & - & - & blue \\
\hline Benzydamine N-oxide standard & - & blue & - & - & blue \\
\hline Benzydamine from the acidic extract & - & blue & - & - & blue \\
\hline Benzydamine from alkaline extract & - & blue & - & - & blue \\
\hline Indomethacin & - & yellow & purple & yellow & - \\
\hline
\end{tabular}

Note:* - reagents-developers: IV. A mixture of $10 \%$ solution of copper sulfate and $2 \%$ ammonia (5: 1 ); V. 1 \% solution of o-toluidine in acetone after $0.3 \mathrm{M}$ solution of copper sulfate; VI. $0.1 \%$ solution of methyl red in ethanol. The chromatogram before and after treatment with the reagent is maintained at $100{ }^{\circ} \mathrm{C}$; VII. Bromocresol green. $0.03 \%$ solution of bromocresol green in $80 \%$ aqueous methanol, to which is added 8 drops of $3 \%$ aqueous $\mathrm{NaOH}$ solution for every $100 \mathrm{ml}$ of reagent; VIII. Bromocresol green, acidified with acetic acid. To $0.1 \%$ alcohol solution of bromocresol green add dropwise to the yellow color $1 \%$ acetic acid

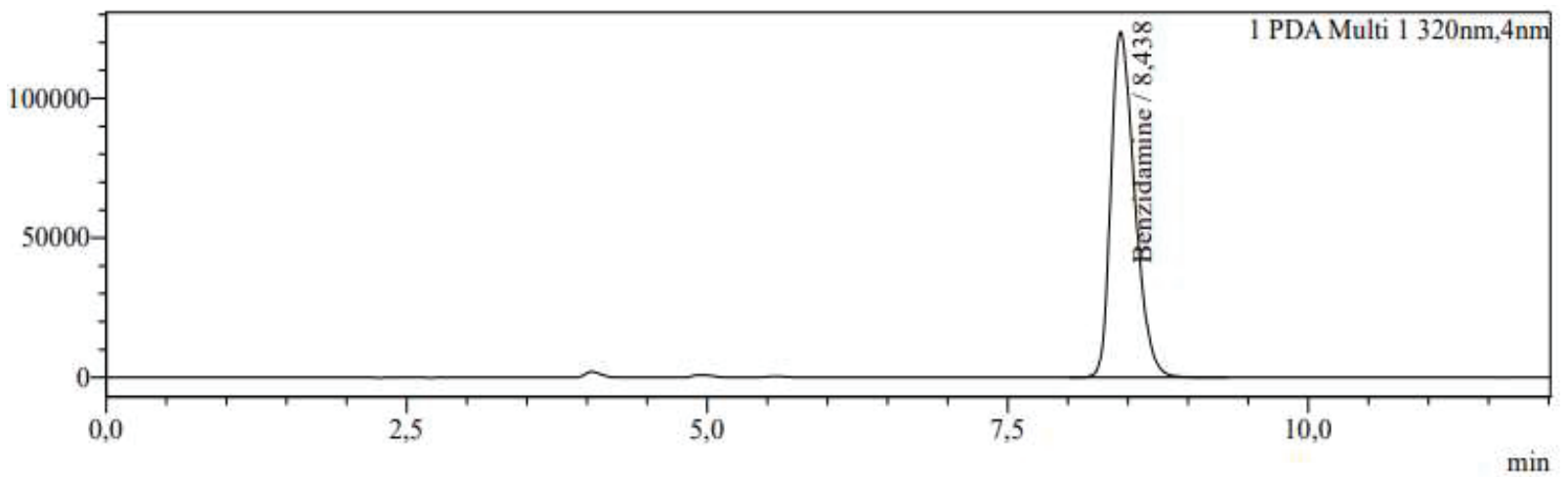

Fig. 4. Chromatogram of a standard solution of benzydamine

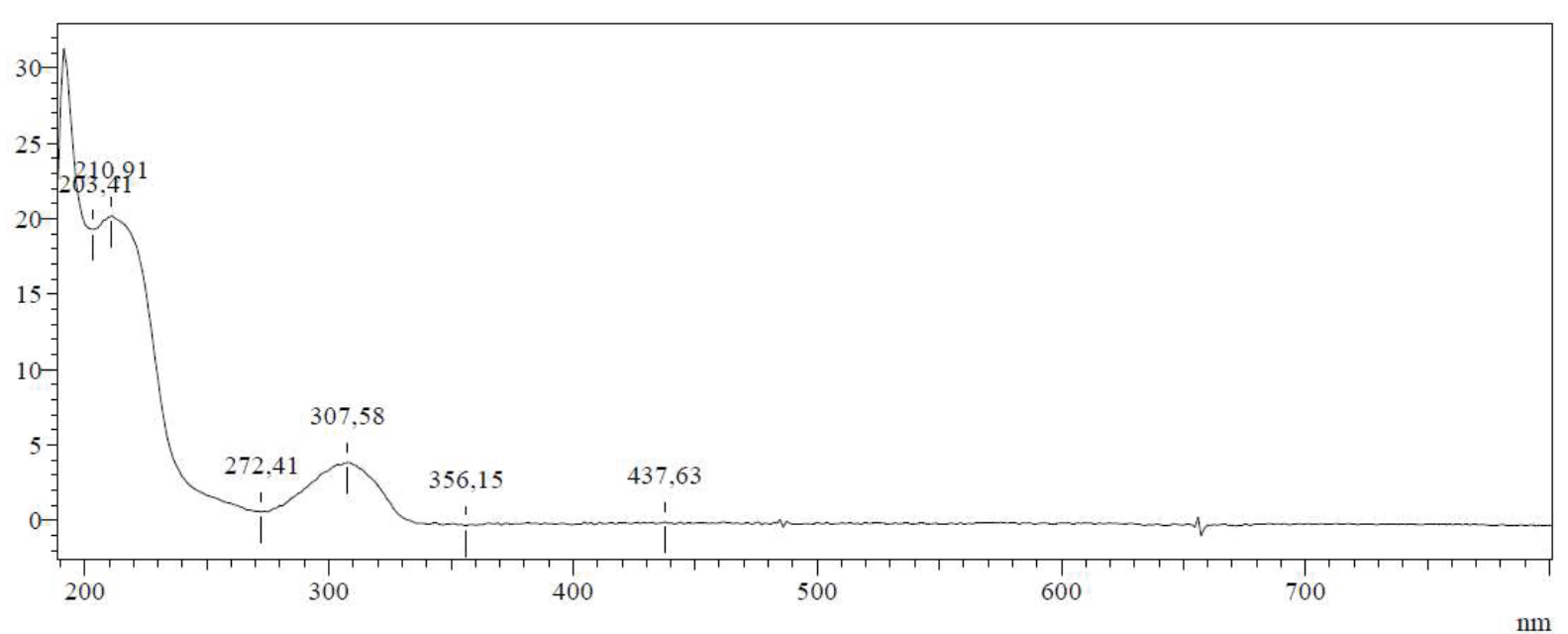

Fig. 5. UV spectrum of benzydamine 
preparative thin layer chromatography. The resulting eluate was evaporated to dryness in the air. The residue was dissolved in a minimum amount of absolute methanol, absolute methanol saturated with hydrogen chloride and diethyl ether were added for turbidity and left to stand for a day in the refrigerator. The precipitate was filtered off, washed with diethyl ether and examined together with pharmacopoeial standards (Benzydamine hydrochloride (BP) - cat No. 610, lot - 3984; Benzy- damine N - oxide (LGC) - cat No. MM0142.08, lot 142.08.09.02) by HPLC (Fig. 8, 9).

HPLC studies were performed in conditions, described above.

To confirm the nature of the main peak and to avoid a possible false-positive conclusion, comparisons of UV spectrum of the test solution were made with the UV spectrum of the benzydamine $\mathrm{N}$-oxide reference solution (Fig. 10, 11).

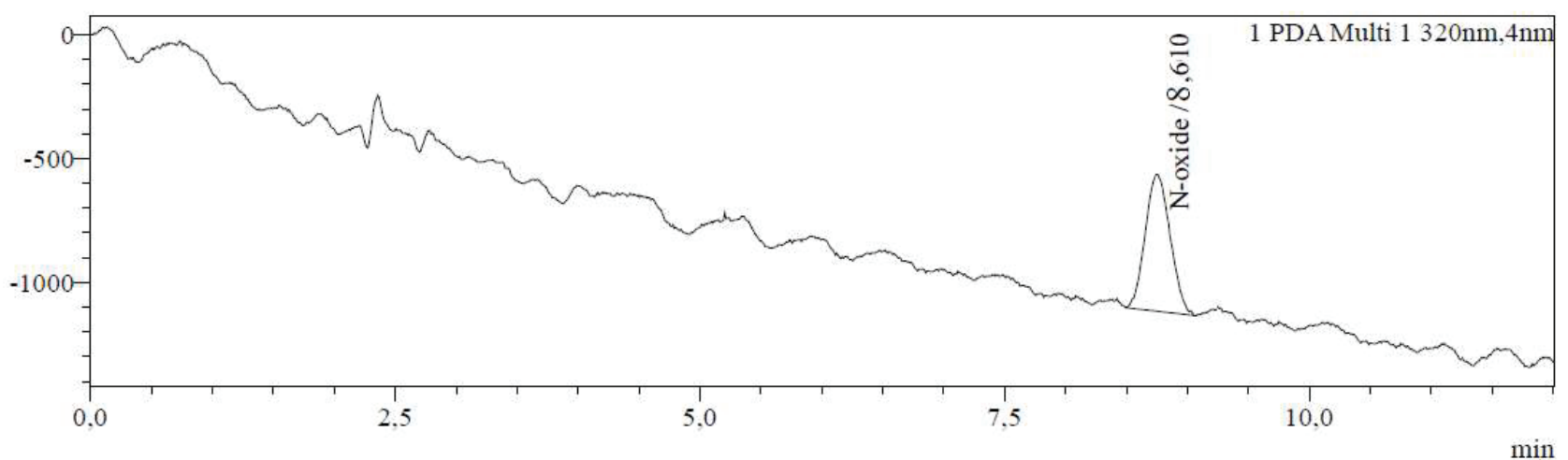

Fig. 6. Chromatogram of a standard solution of benzydamine N-oxide

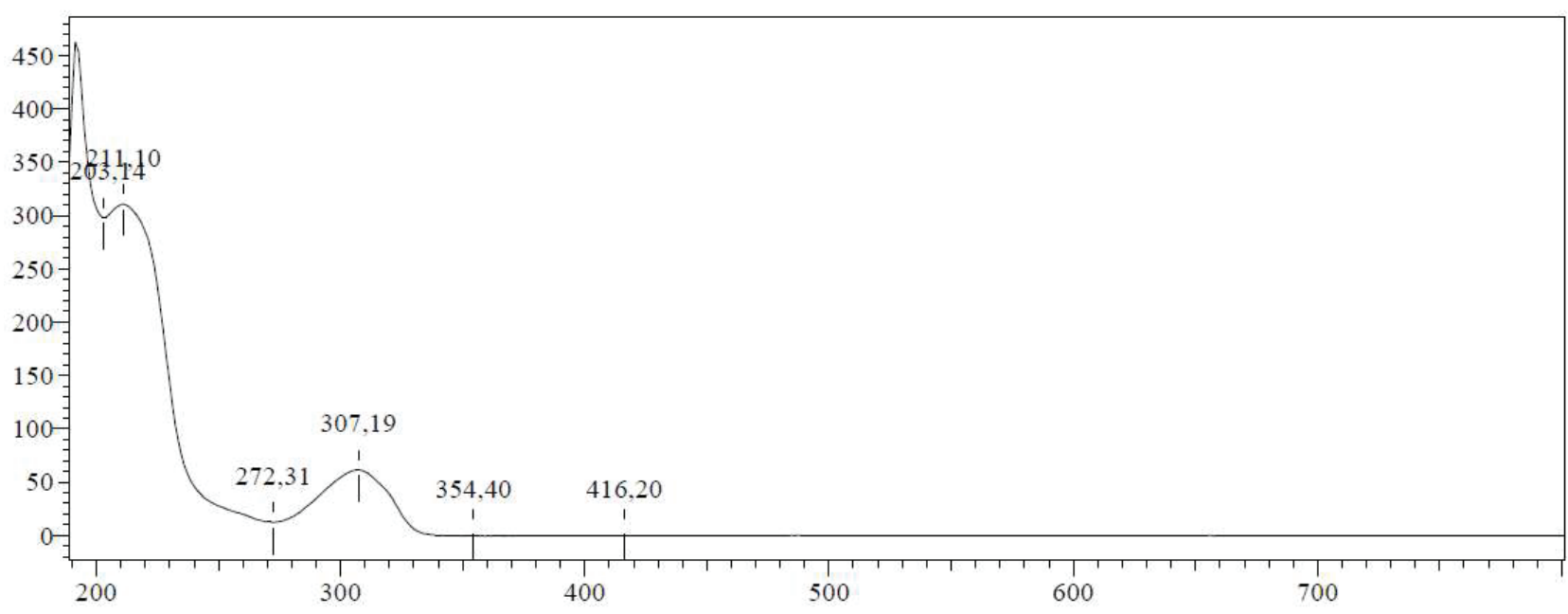

Fig. 7. UV spectrum of benzydamine N-oxide

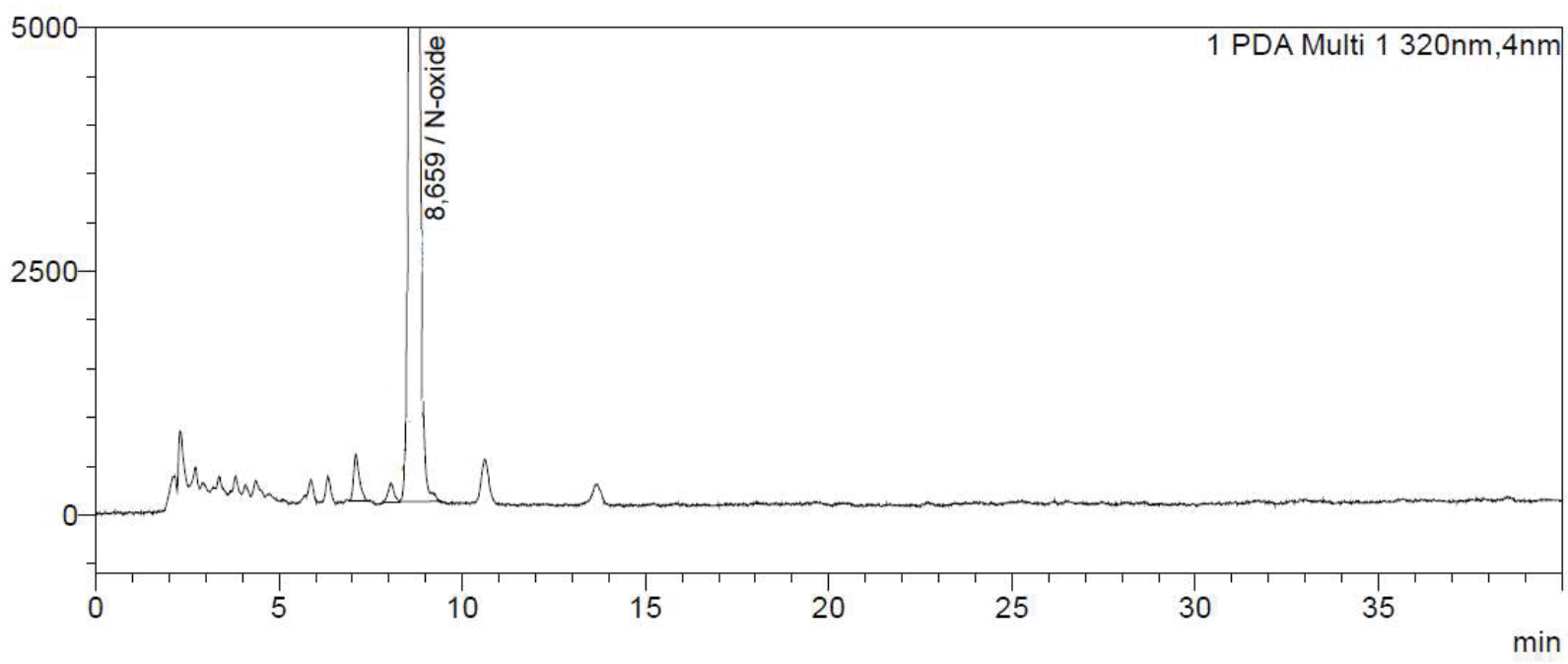

Fig. 8. Chromatogram of acid extract of biomaterial 


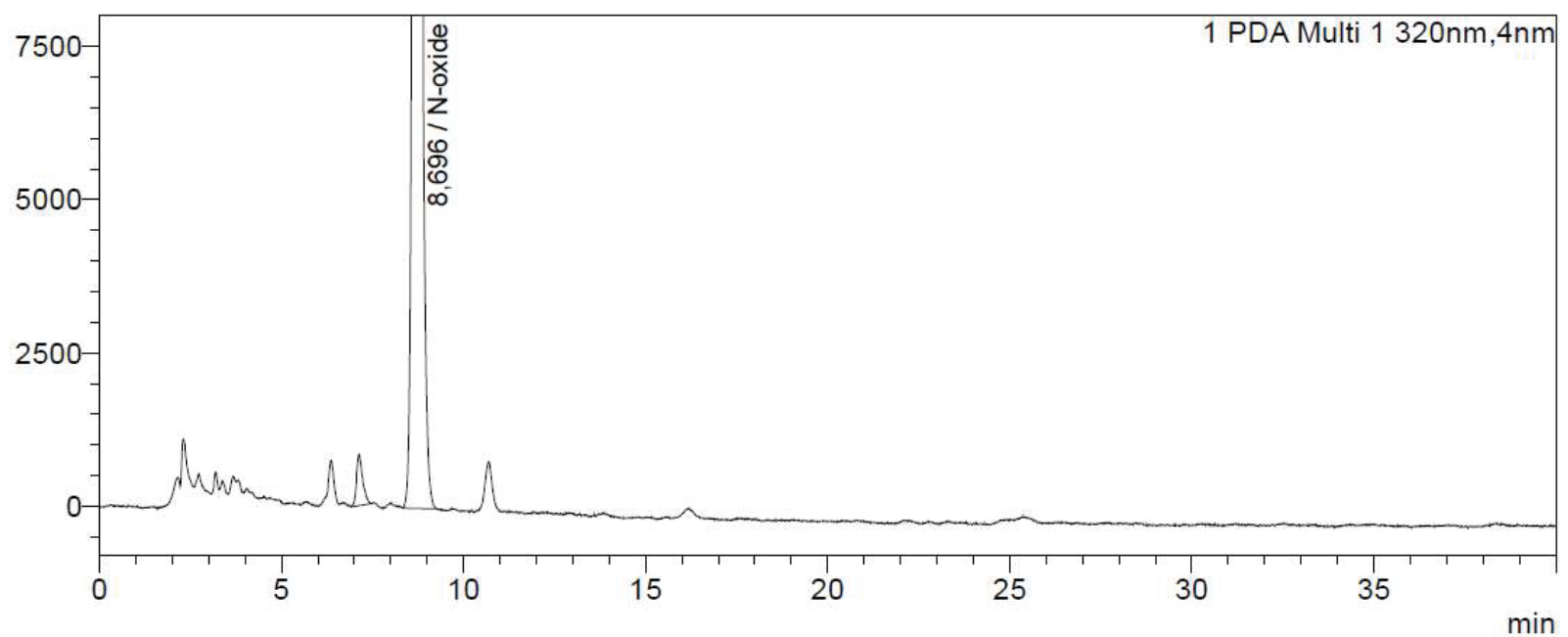

Fig. 9. Chromatogram of alkaline extract

mAU

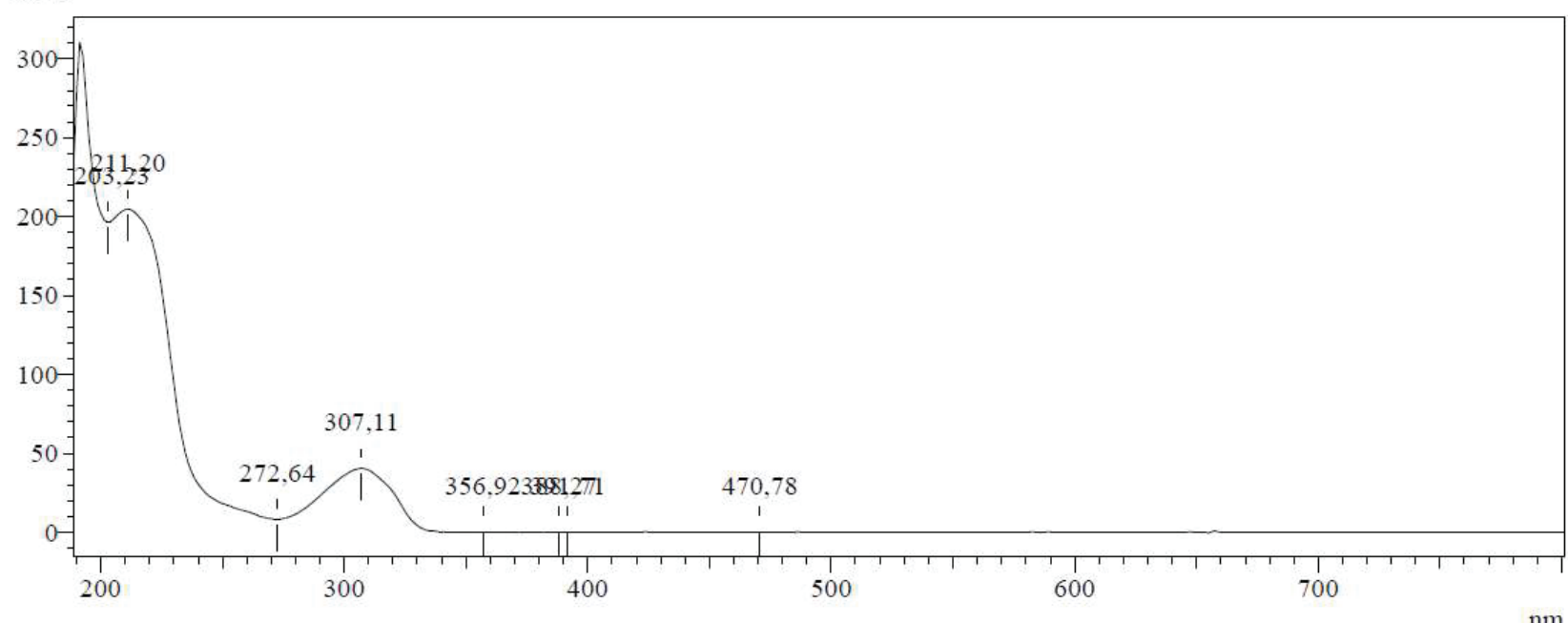

Fig. 10. UV spectrum of the main peak from the chromatogram of the alkaline extract

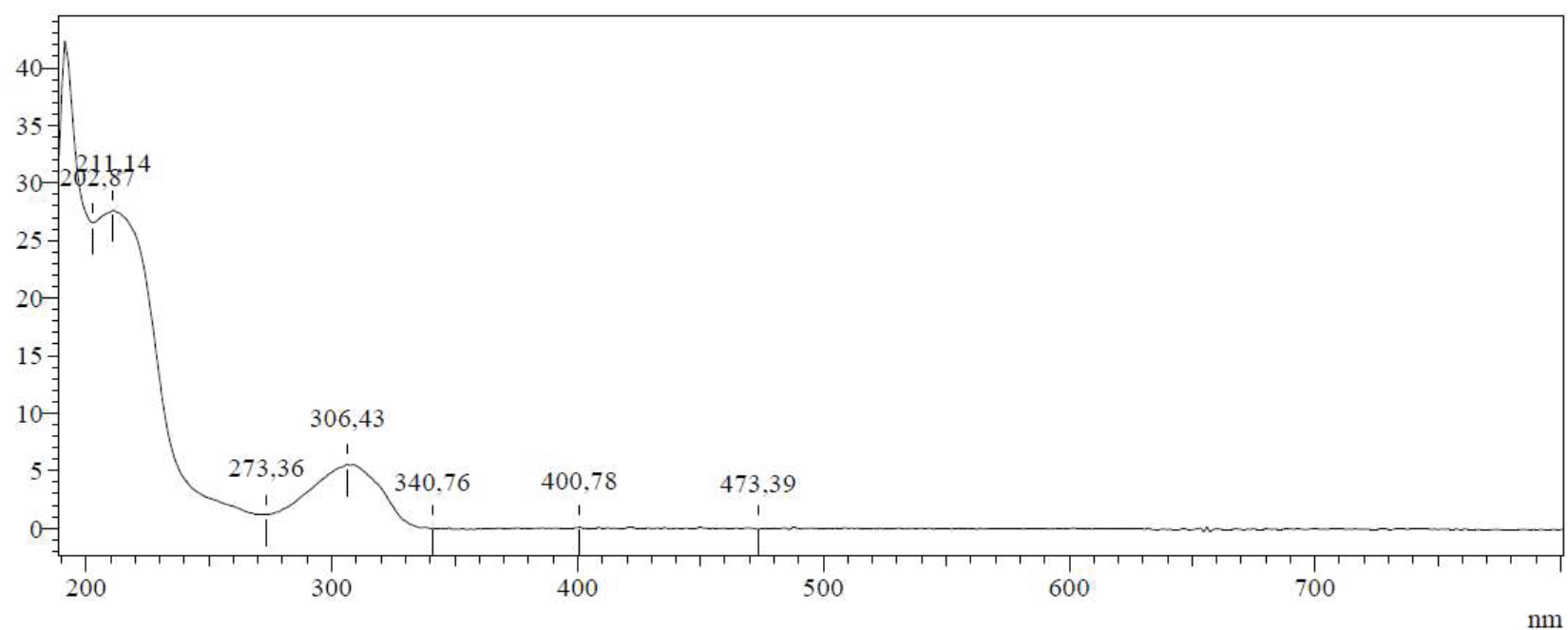

Fig. 11. UV spectrum of the main peak from the chromatogram of the acid extract

\section{Discussion of research results}

Thus, the studies carried out made it possible to obtain results for the reliable detection of benzydamine when carrying out "TLC - screening" among NSAIDs using Mandelin's reagent and subsequent processing of the chromatogram with an additional reagent - bromocresol green, acidified with acetic acid. The resulting blue color is characteristic only of benzydamine and its 
metabolite, in contrast to other NSAIDs. The presence of a peak on the chromatogram of the test solution that coincides with the retention times of the peak of benzydamine N-oxide on the chromatograme of the reference solution, as well as the coincidence of the UV spectra of the peaks, indicate the unambiguous presence of benzydamine N-oxide in the sample. The results of benzydamine and benzydamine N-oxide chromatographic behavior are shown in Table 3.

Table 3

Comparative results of chromatographic distribution of acidic and alkaline urine extracts and pharmacopoeial standards of benzydamine hydrochloride and its metabolite

\begin{tabular}{|c|c|c|}
\hline \multirow{2}{*}{ Substance } & \multicolumn{2}{|c|}{$\begin{array}{c}\text { Chromatographic parame- } \\
\text { ters of content }\end{array}$} \\
\cline { 2 - 3 } & $\begin{array}{c}\text { HPLC method } \\
\text { Retention time, } \\
\text { min }\end{array}$ & TLC hR** \\
\hline Acidic extract of biomaterial & 8.66 & 5 \\
\hline Alkaline extract of biomaterial & 8.69 & 5 \\
\hline $\begin{array}{c}\mathrm{N}-\text { oxide benzydamine refer- } \\
\text { ence standard }\end{array}$ & 8.61 & 5 \\
\hline $\begin{array}{c}\text { Benzydamine hydrochloride } \\
\text { reference standard }\end{array}$ & 8.44 & 57 \\
\hline $\begin{array}{c}\text { hRf* in the system toluene-acetone-ethanol-25 \% ammonia } \\
\text { solution (45:45:7,5:2,5) }\end{array}$ \\
\hline
\end{tabular}

The data from Table 3 indicate that benzydamine $\mathrm{N}$-oxide can be found in both alkaline and acidic extracts, that was confirmed be HPLC method after a preparative separation of biomaterial test solutions.

Study limitations. A limitation of the study is the lack of sensitivity of the method of thin layer chromatography, which does not allow to reliably detect benzydamine in therapeutic concentrations.
Prospects for further research. It is planned to conduct a systematic toxicological study in a number of prohibited narcotic and psychotropic drugs.

\section{Conclusions}

The conditions of extraction of benzydamine and its metabolite $-\mathrm{N}$ - oxide from urine were studied. It has been established that the benzydamine metabolite can be identified in both acidic and alkaline extracts.

The selectivity and sensitivity of reagents commonly used in toxicological screening for the imaging of benzydamine and $\mathrm{N}$ - oxide have been studied. It was found that the use of an alcoholic solution of bromocresol green allows to reliably detect benzydamine and its metabolite in the presence of other NSAIDs.

The chromatographic behavior of benzydamine and $\mathrm{N}$ - oxide in the presence of other NSAIDs similar in pharmacological action was studied. The mobile phase (toluene-acetone-ethanol-25\% ammonia solution (45:45:7.5:2.5)) was proposed, which allows to separate benzydamine and its metabolite from other drugs.

The method of detection and determination of benzydamine and benzydamine $\mathrm{N}-$ oxide in urine by HPLC with diode-array detection has been studied. The obtained results allow to accurately identify the drug that led to the toxic effect.

The coincidence of retention times of the main peak on chromatogram of the test solutions with the retention time of benzydamine $\mathrm{N}$-oxide peak from the chromatogram of the reference solution, as well as the spectras indicate that the main peak on the chromatograms of acidic and alkaline extracts is the peak of benzydamine $\mathrm{N}$-oxide.

\section{Conflict of interests}

The authors of the article do not have a conflict of interests.

\section{Financing}

The study was performed without financial support.

\section{References}

1. Gunaydin, C., Bilge, S. S. (2018). Effects of Nonsteroidal Anti-Inflammatory Drugs at the Molecular Level. The Eurasian Journal of Medicine, 50 (2), 116-121. doi: http://doi.org/10.5152/eurasianjmed.2018.0010

2. Kuriyama, A., Aga, M., Maeda, H. (2018). Topical benzydamine hydrochloride for prevention of postoperative sore throat in adults undergoing tracheal intubation for elective surgery: a systematic review and meta-analysis. Anaesthesia, 73 (7), 889-900. doi: http://doi.org/10.1111/anae.14224

3. Sein Anand, J., Lukasik-Glębocka, M., Paweł Korolkiewicz, R. (2007). Recreational abuse with benzydamine hydrochloride (tantum rosa). Clinical Toxicology, 45 (2), 198-199. doi: http://doi.org/10.1080/15563650600981210

4. Reed, P. (2017). Sussex research reveals the addictive potential of a drug legally available in the UK and other countries. University of Sussex. Available at: https://www.sussex.ac.uk/broadcast/read/40139

5. Opaleye, E. S., Noto, A. R., Sanchez, Z. van der M., Moura, Y. G. de, Galduróz, J. C. F., Carlini, E. A. (2009). Recreational use of benzydamine as a hallucinogen among street youth in Brazil. Revista Brasileira de Psiquiatria, 31 (3), 208-213. doi: http:// doi.org/10.1590/s1516-44462009000300005

6. Mota, D. M., Costa, A. A. da, Teixeira, C. dos S., Bastos, A. A., Dias, M. F. (2010). Use abusive of benzydamine in Brazil: an overview in pharmacovigilance. Ciência \& Saúde Coletiva, 15 (3), 717-724. doi: http://doi.org/10.1590/s1413-81232010000300014

7. Balaban, O. D., Atagun, M. I., Yilmaz, H., Yazar, M. S., Alpkan, L. R. (2013). Benzydamine Abuse as a Hallucinogen: A Case Report. Klinik Psikofarmakoloji Bülteni-Bulletin of Clinical Psychopharmacology, 23 (3), 276-279. doi: http://doi.org/10.5455/ bcp. 20111212083751

8. Can, B., Oz, I., Ozer, H., Simsek, T. (2016). Hallucinations after Ingesting a High Dose of Benzydamine Hydrochloride. Clinical Psychopharmacology and Neuroscience, 14 (4), 407-408. doi: http://doi.org/10.9758/cpn.2016.14.4.407 
9. Acar, Y. A., Kalkan, M., Çetin, R., Çevik, E., Çınar, O. (2014). Acute Psychotic Symptoms due to Benzydamine Hydrochloride Abuse with Alcohol. Case Reports in Psychiatry, 2014, 1-2. doi: http://doi.org/10.1155/2014/290365

10. Gürü, M., Şafak, Y., Cengiz, G. F., Kuru, E., Örsel, S. (2019). Chronic psychosis related to benzydamine hydrochloride abuse. Neurocase, 25 (3-4), 156-158. doi: http://doi.org/10.1080/13554794.2019.1617318

11. Schifano, F., Corazza, O., Marchi, A., Melchiorre, G. D., Sferrazza, E., Enea, A. et. al. (2013). Analysis of online reports on the potential misuse of benzidamine. Rivista di Psichiatria, 48 (3), 182-186. doi: http://doi.org/10.1708/1292.14286

12. Robinson, N. A., Scully, C. (2016). Oral health: Mouthwash abuse. British Dental Journal, 221 (6), 280-280. doi: http://doi.org/ 10.1038/sj.bdj.2016.663

13. Chiappini, S., Guirguis, A., Corkery, J. M., Schifano, F. (2020). Misuse of prescription and over-the-counter drugs to obtain illicit highs: how pharmacists can prevent abuse. Pharmaceutical Journal. doi: http://doi.org/10.1211/pj.2020.20208538

14. Pubchem. Benzydamine (Compound). Available at: https://pubchem.ncbi.nlm.nih.gov/compound/12555\#section=Information-Sources

15. Naser, I. (2006). Izuchenie khromatograficheskogo povedeniia valproevoi kisloty v smesi s drugimi veschestvami kislogo kharaktera. Teoriia ta praktika sudovoi ekspertizi i kriminalistiki, 6, 302-305.

16. Nasser, I. (2008). Rozrobka metodiv analitychnoyi diahnostyky otruyen valproyevoyu kyslotoyu. Kyiv, 163.

17. Catanese, B., Lagana, A., Marino, A., Picollo, R., Rotatori, M. (1986). HPLC determination of benzydamine and its metabolite $\mathrm{N}$-oxide in plasma following oral administration or topical application in man, using fluorimetric detection. Pharmacological Research Communications, 18 (4), 385-403. doi: http://doi.org/10.1016/0031-6989(86)90091-3

18. Cherniy, V. A., Gureeva, S. N., Georgiyants, V. A. (2016). Development and Validation of Alternative Analytical Method for Determination of Related Substances of Benzydamine Hydrochloride in Oral Spray by HPLC. Journal of Drug Design and Medicinal Chemistry, 2 (6), 65-73.

19. Chornyi, V., Chorna, O., Georgiyants, V. (2020). Development and validation of the method for simultaneous determination of Benzydamine hydrochloride and methylparaben in dosage form by HPLC. ScienceRise: Pharmaceutical Science, 3 (25), 12-19. doi: http://doi.org/10.15587/2519-4852.2020.206579

20. Moffat, A. C., Osselton, M. D., Widdop, B. (2011). Clarke’s Analysis of Drugs and Poisons. Pharmaceutical Press, 2736.

Received date 10.11.2021

Accepted date 16.12.2021

Published date 30.12.2021

Olga Chorna, PhD, Department of Common Pharmacy, Educational and Scientific Medical Institute, National Technical University «Kharkiv Politechnic Institute», Kyrpychova str., 2, Kharkiv, Ukraine, 61002

Vasyl Chornyi, PhD, Head of Laboratory, Development Laboratory, JSK Farmak, Kyrilivska str., 63, Kyiv, Ukraine, 04080

Oleksandr Chubenko, PhD, Associate Professor, Department of Clinical Biochemistry, Forensic Toxicology and Pharmacy, Kharkiv Medical Academy of Postgraduate Education, Amosova str., 58, Kharkiv, Ukraine, 61176

Ihor Hrubnyk, PhD, Associate Professor, Department of Common Pharmacy, Educational and Scientific Medical Institute, National Technical University «Kharkiv Politechnic Institute», Kyrpychova str., 2, Kharkiv, Ukraine, 61002

Volodymyr Mishchenko, PhD, Associate Professor, Department of Quality, Standardization and Certification of Medicines, Institute for Advanced Training of Pharmacy Specialists of National University of Pharmacy, Zahysnykiv Ukrainy sq., 17, Kharkiv, Ukraine, 61001

Mykola Golik, Doctor of Pharmaceutical Sciences, Head of Department, Department of Inorganic and Physical Chemistry, National University of Pharmacy, Pushkinska str., 53, Kharkiv, Ukraine, 61002

*Corresponding author: Olga Chorna, e-mail: ovchorna@i.ua 